\title{
Evodiamine alleviates severe pneumonia induced by methicillin-susceptible Staphylococcus aureus following cytomegalovirus reactivation through suppressing NF-кB and MAPKs
}

\author{
$\mathrm{XIN} \mathrm{CHEN}^{1 *}, \mathrm{SHUJUN}_{\mathrm{ZHOU}}{ }^{2 *}$ and $\mathrm{HUI} \mathrm{LI}^{2}$ \\ Departments of ${ }^{1}$ Emergency and ${ }^{2}$ Critical Care Medicine, The Third Affiliated Hospital of Soochow University, \\ The First People's Hospital of Changzhou, Changzhou, Jiangsu 213003, P.R. China
}

Received March 14, 2018 ; Accepted July 25, 2018

DOI: $10.3892 /$ ijmm.2018.3929

\begin{abstract}
Viral and bacterial severe pneumonia are leading causes of mortality across the globe. Evodiamine (Evo), a botanical alkaloid, has anti-inflammatory and antibacterial properties. In the present study, the effect of Evo on severe pneumonia induced by methicillin-susceptible Staphylococcus aureus (MSSA) following cytomegalovirus (CMV) reactivation, and its mechanism, were evaluated. In vitro, the protein and mRNA expression levels of inflammatory cytokines were determined by enzyme-linked immunosorbent assay and reverse transcription-quantitative polymerase chain reaction analysis, respectively. The expression levels of associated proteins of the nuclear factor (NF) $-\kappa \mathrm{B}$ and mitogen-activated protein kinase (MAPK) signaling pathways were measured by western blot analysis. In vivo, mortality rate, weight loss, histological changes, lung bacteria count, inflammatory cytokines, and the expression proteins of associated with the NF- $\mathrm{NB}$ and MAPK signaling pathways were examined. The results revealed that Evo dose-dependently reduced the protein and mRNA expression levels of tumor necrosis factor (TNF)- $\alpha$, interleukin (IL)- 6 and IL-1 $\beta$, and inhibited the levels of phosphorylated (p-) inhibitor of $\mathrm{NF}-\kappa \mathrm{B} \alpha$, p-extracellular signal-regulated kinase, $\mathrm{p}$-c-Jun $\mathrm{N}$-terminal kinase and p-p38, and decreased the nuclear translocation of NF- $\kappa \mathrm{B} / \mathrm{p} 65$ in BEAS-2B cells infected with MSSA. Furthermore, Evo markedly improved survival rate, decreased
\end{abstract}

Correspondence to: Ms. Hui Li, Department of Critical Care Medicine, The Third Affiliated Hospital of Soochow University, The First People's Hospital of Changzhou, 185 Juqian Street, Changzhou, Jiangsu 213003, P.R. China

E-mail: lihuisuda2017@163.com

"Contributed equally

Key words: evodiamine, severe pneumonia, methicillin-susceptible Staphylococcus aureus, cytomegalovirus, nuclear factor- $\kappa \mathrm{B}$, mitogen-activated protein kinases body weight loss and bacterial count, and attenuated lung histological alterations and the levels of inflammatory factors. In addition, the NF- $\mathrm{NB}$ and MAPK signaling pathways were significantly inhibited. Taken together, Evo effectively alleviated pneumonia via the NF- $\kappa \mathrm{B}$ and MAPK pathways and may be a potential therapeutic agent for treating severe pneumonia.

\section{Introduction}

Pneumonia is a major global public health concern. Viral and bacterial pneumonias are major causes of mortality in children, the elderly, the immunodeficient, and those with comorbidities worldwide (1). It is responsible for 120,000,000 episodes and a mortality rate of $1,000,000$ each year in children $<5$ years old (2). Cytomegalovirus (CMV) is one of the most common causes of lung infection in the host lung. Studies have reported that CMV infection can cause acute respiratory distress syndrome and severe lung infection (3). CMV is a species-specific $\beta$-herpes virus, which establishes life-long latent infections in 70-100\% of the world's population and is capable of causing diseases with high morbidity and mortality rates in at-risk immunocompromised populations $(4,5)$. Following primary infection, although typically asymptomatic during the latency period, CMV persists in myeloid precursor cells and becomes latent in several organs, particularly the lungs (6). It can reactivate when there is a certain degree of immunosuppression. Once the virus is reactivated, it can modulate the immune response of the host through the accelerated expression of different genes (7). Furthermore, under certain conditions, the virus can affect several organs and systems, including the lungs, liver, kidneys, salivary glands and mammary glands, and eventually lead to serious diseases (8). When CMV damages an organ or system of the host, it can cause several diseases, including CMV pneumonia (9). Although CMV pneumonia can generally be controlled by lifelong administration of antiviral drugs, including ganciclovir, these drugs require frequent dosing and can potentially cause harmful side-effects. Therefore, developing novel therapies for pneumonia is urgently required.

Evodiamine (Evo), the structure of which is shown in Fig. 1A, is an alkaloidal component extracted from the fruit of Evodia rutaecarpa (Juss) Benth. Previous studies have shown 
that Evo can attenuate chronic high-glucose challenge inflammatory injury (10), protect septic mice against acute lung injury (11), restrain tumor activity in several types of human cancer (12-14), and improve acute inflammatory cerebral ischemia (15). However, the effect of Evo on severe pneumonia remains to be fully elucidated. Therefore, the present study aimed to evaluate the roles and underlying mechanisms of Evo on severe pneumonia induced by Methicillin-susceptible Staphylococcus aureus (MSSA) following CMV reactivation in vitro and in vivo.

\section{Materials and methods}

Reagents and materials. Evo was provided by the National Institute for the Control of Pharmaceuticals and Biological Products (Beijing, China). Evo was suspended in 100\% dimethylsulfoxide. Enzyme-linked immunosorbent assay (ELISA) kits were obtained from the Jiancheng Bioengineering Institute of Nanjing (Nanjing, China. The antibodies used were as follows: Antibodies against p65 (cat. no. ab16502; Abcam, Cambridge, UK), Lamin A (cat. no. ab26300; Abcam), phosphorylated

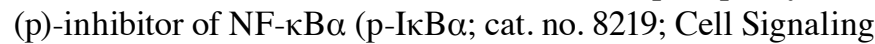
Technology, Inc., Danvers, MA, USA), IкB $\alpha$ (cat. no. 9242S; Cell Signaling Technology, Inc.), c-Jun N-terminal kinase (JNK; cat. no. ab176662; Abcam), p-JNK (cat. no. ab207477; Abcam), extracellular signal-regulated kinase (Erk; cat. no. ab176641; Abcam), p-Erk (cat. no. ab192591; Abcam), p-p38 (cat. no. ab178867; Abcam), p38 (cat. no. ab32142; Abcam)and $\beta$-actin (cat. no. ab8226; Abcam).

Cells and strains. MSSA (ATCC 25923; American Type Culture Collection, Manassas, VA, USA) strains producing staphylococcal pneumonia were isolated from clinical samples, grown in Luria Bertani (LB) medium and conserved at $-80^{\circ} \mathrm{C}$ in $50 \%$ LB broth and $50 \%$ glycerol. The BEAS-2B cell line was purchased from the Shanghai Institute of Cell Biology in the Chinese Academy of Sciences (Shanghai, China) and cultivated in RPMI-1640 (Gibco; Thermo Fisher Scientific, Inc., Waltham, MA, USA). The media were supplemented with $10 \%$ FBS (Gibco; Thermo Fisher Scientific, Inc.) and maintained in a humidified incubator at $37^{\circ} \mathrm{C}$ with $5 \% \mathrm{CO}_{2}$. NIH3T3 cells were purchased from Wuhan University Preservation Center (Wuhan, China). The Murine CMV (MCMV) Smith strain (ATCC-VR-1399) was ordered from the American Type culture Collection. The MCMV strain was propagated on NIH3T3 cells and titrated on the mouse embryo fibroblasts as described previously (16).

MTT assay. The BEAS-2B cells were cultured in RPMI-1640 supplemented with $10 \%$ FBS. The cells were stimulated for $24 \mathrm{~h}$ at $37^{\circ} \mathrm{C}$ with different concentrations of Evo (20-100 $\mu \mathrm{M}$; $20,40,60,80$ and $100 \mu \mathrm{M})$. Subsequently, $20 \mu \mathrm{l}$ of $5 \mathrm{mg} / \mathrm{ml}$ MTT solution was added and the plate was incubated at $37^{\circ} \mathrm{C}$ for $4 \mathrm{~h}$. Following aspiration and washing with PBS, $150 \mu \mathrm{l}$ of DMSO was added to each well. The absorbance was determined spectrophotometrically at $490 \mathrm{~nm}$ on an ELX800 UV universal microplate reader.

Infection of cells with MSSA. The BEAS-2B cells incubated with $1 \mathrm{~mL}$ of RPMI-1640 containing the MSSA with the indicated multiplicity of infection $\left(1 \times 10^{5} \mathrm{CFU}\right)$ at $37^{\circ} \mathrm{C}$ in $5 \%$ $\mathrm{CO}_{2}$. After $3 \mathrm{~h}$, the suspension was aspirated, and the cells were washed with PBS and incubated with Evo (10, 20 and $40 \mu \mathrm{m})$ for $24 \mathrm{~h}$.

Animal model. Pathogen-free female BALB/c mice $(n=90$; 6 weeks old; $22-25 \mathrm{~g}$ ) were supplied by the Animal Center of Soochow University (Changzhou, China; certificate no. SCXK 2015-0004). The mice were housed individually in steel microisolator cages at $22^{\circ} \mathrm{C}$ with a $12 / 12$-h light/dark cycle, and fed a standard laboratory diet and water Animal welfare and experimental procedures and was approved by the Animal Experimental Ethical Committee of Soochow University.

The procedures of animal model establishment were performed as previously described (16). Following anesthetization, the BALB/c mice were infected by intra-peritoneal injection with $3 \times 10^{4}$ PFU MCMV Smith strain or saline. At 4 months post-MCMV primary infection, all mice underwent cecal ligation and puncture (CLP) to trigger viral reactivation in the MCMV groups. Briefly, the mice were anesthetized under sodium pentobarbital following cutaneous asepsis. A 5-mm incision in the lower-right quadrant of the abdomen was introduced, and the cecum was localized and ligatured $3 \mathrm{~mm}$ above its extremity using an $18 \mathrm{G}$ needle. The abdomen was then sutured, and cutaneous asepsis was performed with 5\% alcoholic povidone. After $24 \mathrm{~h}$, the animals were administered with an intraperitoneal injection of $0.01 \mathrm{mg} / \mathrm{g}$ of tramadol. At 14 days post-CLP, the surviving mice in all groups received an intranasal inoculation with $50 \mu \mathrm{L} 5 \times 10^{8} \mathrm{CFU}$ MSSA to induce severe pneumonia.

Experimental designs. The mice were randomly divided into five groups: Control group (saline + CLP + MSSA); model group (MCMV + CLP + MSSA); and Evo groups (MCMV $+\mathrm{CLP}+\mathrm{MSSA}+5,10$, or $20 \mathrm{mg} / \mathrm{kg}$ Evo). Each group was divided into two sub-groups: 5 and 15 days. Following intranasal inoculation with MSSA, the mice were intragastrically administrated with different concentrations of Evo $(5,10$, and $20 \mathrm{mg} / \mathrm{kg}$ ), which were selected according to the preliminary experiments, whereas mice in the control and MCMV groups received an equal volume of distilled water of $0.5 \%$ Tween- 80 , once per day for a period of 15 days. In the 15-day cohort, the daily weight was closely monitored every 5 days and spontaneous mortality of the animals was noted during this period. On days 5 and 15, all surviving mice were sacrificed with a lethal dose of thiopental, and samples of blood and the lungs were subjected to further analysis.

Histological analysis. The animals were sacrificed at 5 and 15 days post-treatment. The lungs were removed and embedded in paraffin, cut into $3 \mathrm{~mm}$ sections, and stained with hematoxylin and eosin. Subsequently, pathological changes were evaluated under a light microscope.

Bacterial counts in lung tissues. The lung tissues were crushed and homogenized in $1 \mathrm{ml}$ of PBS to determine the lung bacterial count. Serial 10-fold dilutions of the lung homogenates were cultured using a $5 \%$ horse blood (BioMerieux, SA., Marcy-l'Etoile, France) agar plate at $37^{\circ} \mathrm{C}$ under anaerobic conditions. Following bacterial culture, identification of the 
Table I. Oligonucleotide primers used for reverse transcription-quantitative polymerase chain reaction analysis.

\begin{tabular}{ll}
\hline Name & \multicolumn{1}{c}{ Primer sequence (5'-3') } \\
\hline TNF- $\alpha$ & Forward: CTTCTCATTCCTGCTTGTG \\
& Reverse: ACTTGGTGGTTTGCTACG \\
IL-1 $\beta$ & Forward: AGGCTCCGAGATGAACAA \\
& Reverse: AAGGCATTAGAAACAGTCC \\
IL-6 & Forward: TTCTTGGGACTGATGCTG \\
& Reverse: CTGGCTTTGTCTTTCTTGTT \\
gB & Forward: GTCGGCCATCTACGAGAGAC \\
$\beta$-actin & Reverse: GACCAGCGGTCTCGAATAAC \\
& Forward: AACAGTCCGCCTAGAAGGAC \\
& Reverse: CGTTGACTACCGTAAAGACC \\
\hline
\end{tabular}

TNF- $\alpha$, tumor necrosis factor- $\alpha$; IL, interleukin; gB, glycoprotein-B.

colonies was performed by culture on Chapman medium (Bertin Pharma (Montigny le Bretonneux, France) and confirmed using matrix-assisted laser desorption/ionisation-time-of-flight mass spectrometry.

ELISA analysis. The concentrations of cytokines in the cell culture medium and mouse serum collected by cardiac puncture at 5 and 15 days post-infection with MSSA were determined by ELISA for mouse tumor necrosis factor (TNF)- $\alpha$, interleukin (IL)-6, IL-1 $\beta$, interferon (IFN)- $\alpha$ and IFN- $\gamma$ following the manufacturer's protocol. Serum was separated by centrifugation at $400 \mathrm{x}$ g for $10 \mathrm{~min}$ at $4^{\circ} \mathrm{C}$ and stored at $-80^{\circ} \mathrm{C}$. The 96 -well microplates were read using an ELX800 UV universal microplate reader at $450 \mathrm{~nm}$.

Reverse transcription-quantitative polymerase chain reaction (RT-qPCR) assay. Total RNA of the lung tissue was obtained using TRIzol reagent. The reverse transcription reactions for mRNA were performed using PrimeScript ${ }^{\mathrm{TM}}$ RT Master mix (Promega Corporation, Madison, WI, USA). The RT-qPCR analysis was performed using Taq polymerase (Takara Biotechnology Co., Ltd., Dalian, China) consisting of a final volume of $20 \mu \mathrm{l}$, containing $2 \mu \mathrm{l}$ cDNA, $10 \mu \mathrm{l}$ SYBR-Green Mix, $4 \mu \mathrm{l}$ primer mix and $4 \mu \mathrm{lddH} 2 \mathrm{O}$ (Takara Biotechnology Co., Ltd.). Primers specific for the TNF- $\alpha$, IL-6, IL-1 $\beta$, glycoprotein-B $(\mathrm{gB})$ gene and $\beta$-actin are listed in Table I. $\beta$-actin was selected as an internal control to normalize target gene expression. Thermocycling conditions were as follows: $95^{\circ} \mathrm{C}$ for $5 \mathrm{~min}$ followed by 40 cycles of $95^{\circ} \mathrm{C}$ for $10 \mathrm{sec}$ and $60^{\circ} \mathrm{C}$ for $30 \mathrm{sec}$, then a melting curve analysis from $60^{\circ} \mathrm{C}$ to $95^{\circ} \mathrm{C}$ every $0.2^{\circ} \mathrm{C}$ for $1.5 \mathrm{~min}$ was obtained. The transcript amount was normalized to U6 and $\beta$-actin and quantified using the $2^{-\Delta \Delta \mathrm{Cq}}$ method (17).

Western blot analysis. The western blot analysis was performed as described previously (15). Protein samples were extracted from the cells or tissues with Protein Extraction Reagent (Pierce; Thermo Fisher Scientific, Inc.). Subsequently, the protein concentration was measured using a bicinchoninic acid protein assay kit (Sangon Biotech Co., Ltd., Shanghai,
China). Total protein $(20 \mu \mathrm{g})$ in each sample was separated using SDS-PAGE (10\% gel) and transferred onto a polyvinylidene difluoride filter membrane. The membrane was blocked using $5 \%$ non-fat milk at $25^{\circ} \mathrm{C}$ for $1 \mathrm{~h}$, and then incubated with primary antibodies overnight at $4^{\circ} \mathrm{C}$. Antibodies against IкB $\alpha$ (cat. no. 9242S; 1:1,000; Cell Signaling Technology, Inc.), p-IкB $\alpha$ (cat. no. 8219; 1:1,000; Cell Signaling Technology, Inc.), NF-кB p65 (cat. no. ab16502; 1:500; Abcam), JNK (cat. no. ab176662; 1:1,000; Abcam), p-JNK (cat. no. ab207477; 1:1,000; Abcam),Erk (cat. no. ab176641; 1:1,000; Abcam),p-Erk (cat. no. ab192591; 1:1,000; Abcam), p38 (cat. no. ab32142; 1:1,000; Abcam), p-p38 (cat. no. ab178867; 1:1,000; Abcam), $\beta$-actin (cat. no. ab8226; 1:3,000; Abcam) and Lamin A (cat. no. ab26300; 1:3,000; Abcam) were used. $\beta$-actin and Lamin A were used as internal controls. Then, the membrane was incubated with anti-goat HRP-conjugated antibody (cat. no. AR1017; 1:5,000; Boster Systems, Inc., Pleasanton, $\mathrm{CA}, \mathrm{USA})$ at $25^{\circ} \mathrm{C}$ for $2 \mathrm{~h}$. Detection was executed with the Odyssey infrared imaging system (LI-COR Biosciences, Lincoln, NE, USA). The immunoreactive bands were detected by enhanced chemiluminescence (Pierce; Thermo Fisher Scientific, Inc., Waltham, MA, USA).

Statistical analysis. Statistical analysis of data was performed with GraphPad Prism 5 software (GraphPad Software, Inc., La Jolla, CA, USA) One-way analysis of variance was used for multiple group comparison; Student's t-test was performed when only two groups were compared. Results were expressed as the mean \pm standard deviation. $\mathrm{P}<0.05$ was considered to indicate a statistically significant difference.

\section{Results}

Evo inhibits inflammatory cytokines in vitro. The results of the MTT assay showed that Evo had no effect on the cell viability of BEAS-2B cells between concentrations of 0 and $60 \mu \mathrm{M}$ (Fig. 1B). Evo markedly decreased the protein levels of TNF- $\alpha$, IL- 6 and IL- $1 \beta$, whereas MSSA infection increased these levels (Fig. 1C). RT-qPCR analysis showed elevated mRNA expression levels of TNF- $\alpha$, IL-1 $\beta$ 
A<smiles>CN1c2ccccc2C(=O)N2CCc3c([nH]c4ccccc34)C21</smiles>
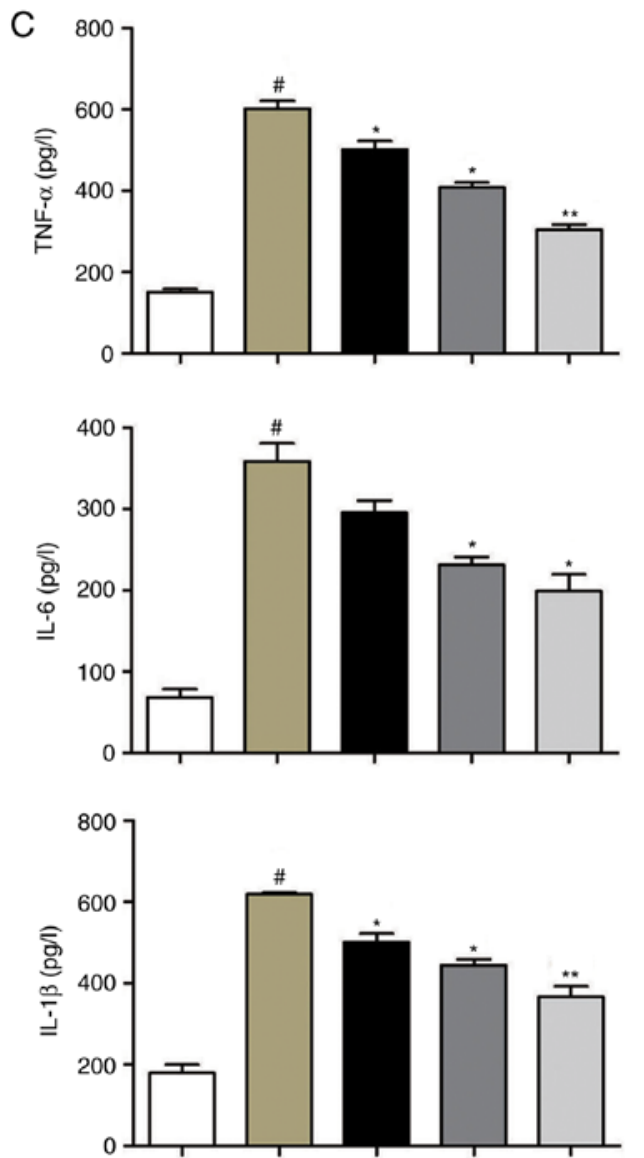

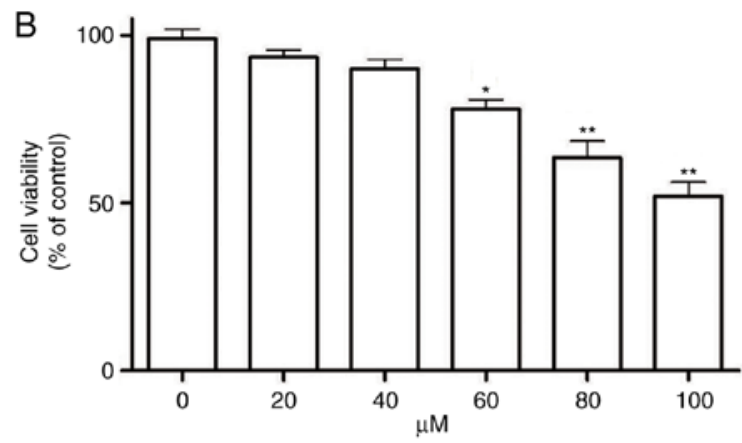

D
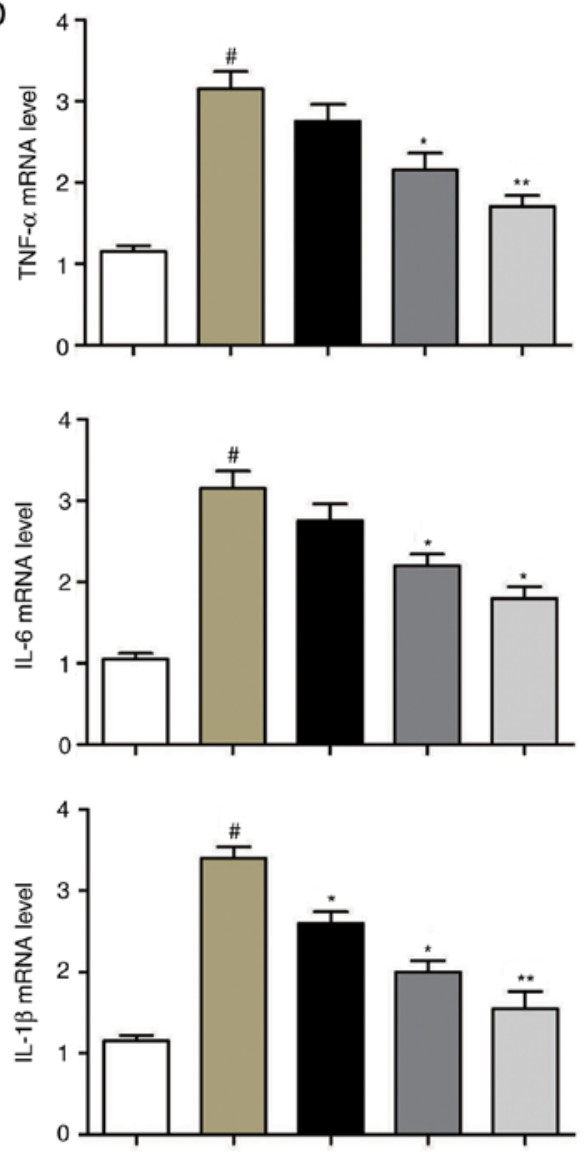

Figure 1. Effects of Evo on inflammatory cytokines in vitro. (A) Structure of Evo. Effects of Evo on (B) cell vitality, and the (C) protein and (D) mRNA levels of TNF- $\alpha$, IL-1 $\beta$ and IL-6 in BEAS-2B cells infected with MSSA. Data are shown as the mean \pm standard deviation. ${ }^{\# \#} \mathrm{P}<0.01$, vs. control group; ${ }^{*} \mathrm{P}<0.05$ and ${ }^{* *} \mathrm{P}<0.01$, vs. MSSA (Model) group. Evo, evodiamine; MSSA, methicillin-susceptible Staphylococcus aureus; TNF- $\alpha$, tumor necrosis factor- $\alpha$; IL, interleukin.

and IL-6 following MSSA infection, whereas Evo (20 and $40 \mu \mathrm{M})$ dose-dependently reduced the mRNA expression levels (Fig. 1D).

Evo inhibits $N F-\kappa B$ and MAPK pathways in vitro. As shown in Fig. 2A, MSAA infection markedly induced the nuclear translocation of NF- $\kappa \mathrm{B} / \mathrm{p} 65$ and $\mathrm{p}-\mathrm{I} \kappa \mathrm{B} \alpha$, whereas Evo led to marked repression of these trends in a dose-dependent manner. In addition, Evo reduced the phosphorylation of JNK, ERK and p38 MAPKs (Fig. 2B).

Evo reduces mortality rates. As shown in Fig. 3A, the accumulative mortality rates during 15 days with Evo doses of 5, 10 and $20 \mathrm{mg} / \mathrm{kg}$ were 65,44 and $29 \%$, respectively, whereas the mortality rate in the MCMV group was $73 \%$. Evo (10 and $20 \mathrm{mg} / \mathrm{kg}$ ) dose-dependently improved the survival rate, compared with that in the MCMV groups.

Evo decreases body weight loss. Compared with the control group, the MCMV mice showed a trend towards increased weight loss. The weight loss in the Evo (10 and $20 \mathrm{mg} / \mathrm{kg}$ ) groups were lower than that in the MCMV group, whereas the weight loss in the Evo $(5 \mathrm{mg} / \mathrm{kg})$ group showed no statistical significance (Fig. 3B).

Histological assessment. Morphological examination of the lungs from the MCMV mice sacrificed on days 5 and 15 post-MSSA pneumonia revealed voluminous right or left 

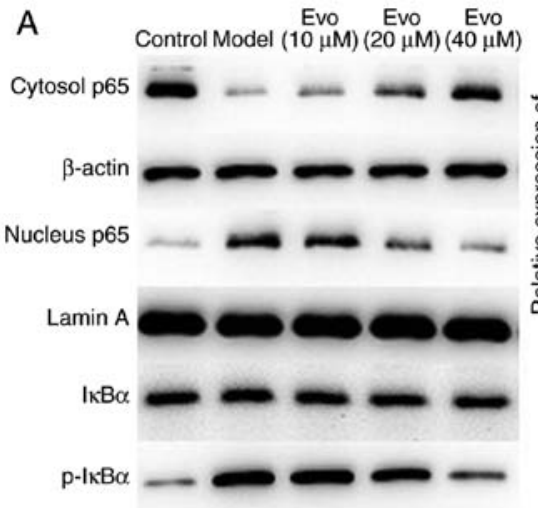

B
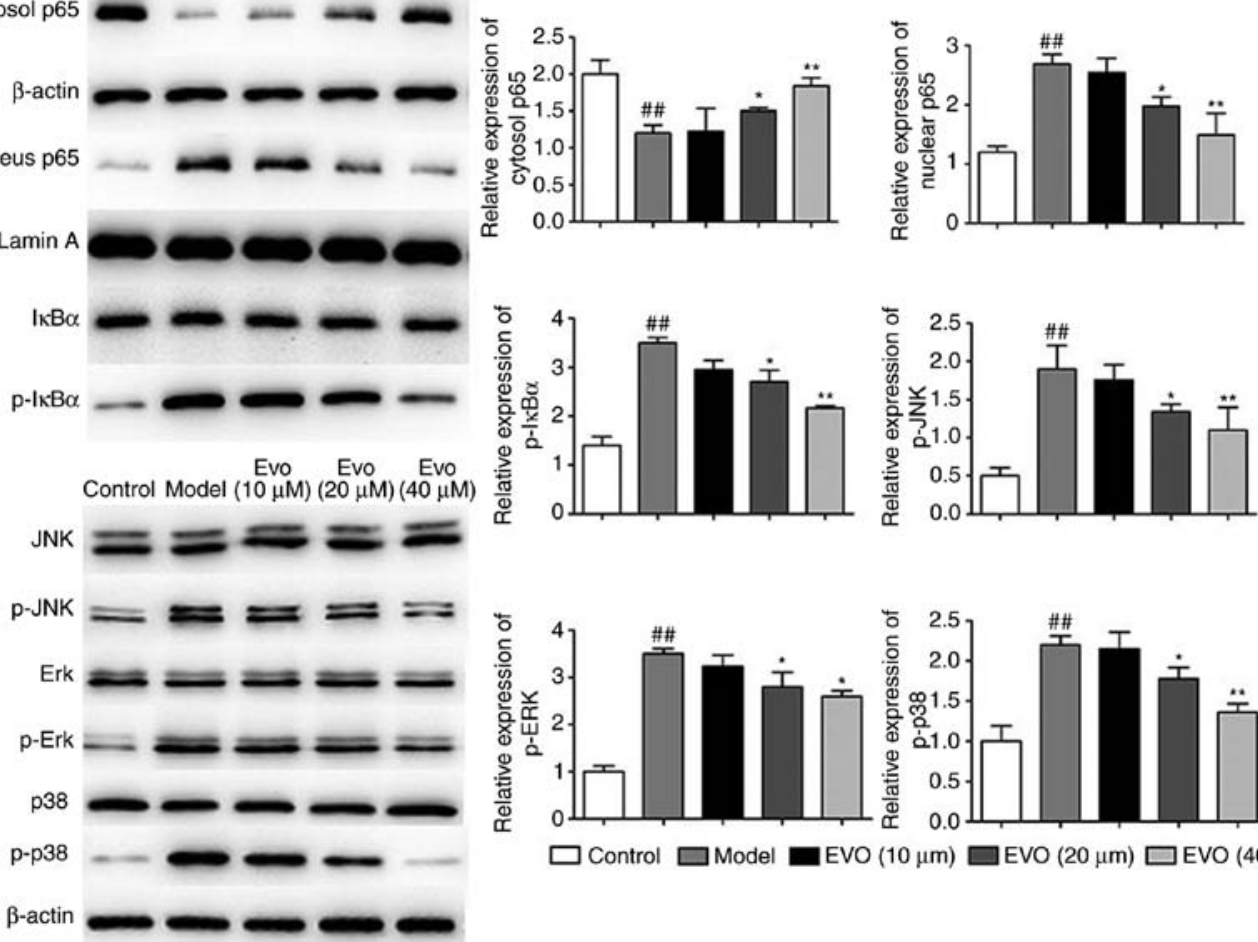

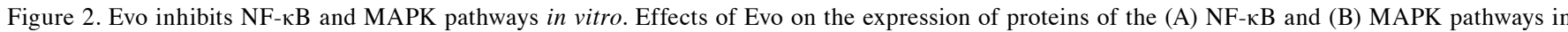
BEAS-2B cells infected with MSSA. Data are shown as the mean \pm standard deviation. ${ }^{\# \#} \mathrm{P}<0.01$, vs. control group; ${ }^{*} \mathrm{P}<0.05$ and ${ }^{* * *} \mathrm{P}<0.01$, vs. MSSA group.

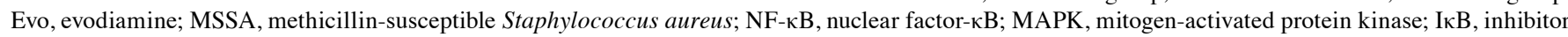
of NF-кB; JNK, c-Jun N-terminal kinase; Erk, extracellular signal-regulated kinase; p-, phosphorylated.
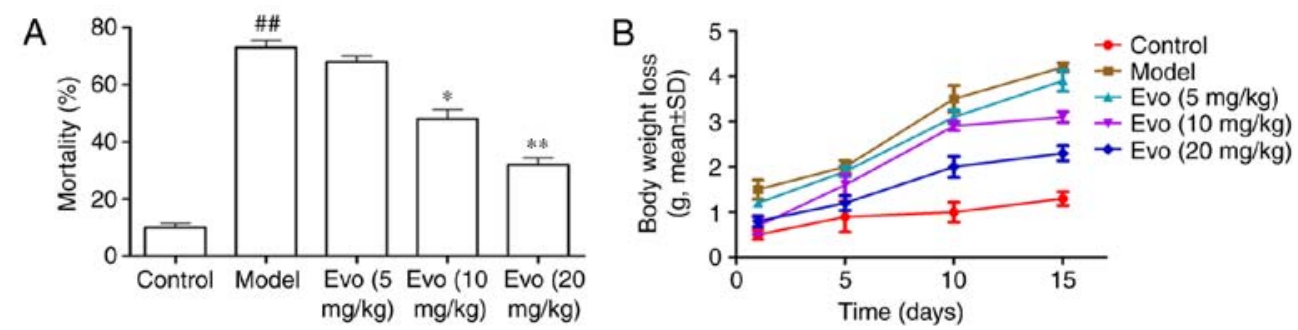

C

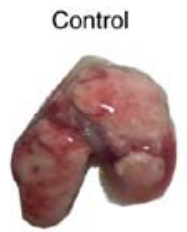

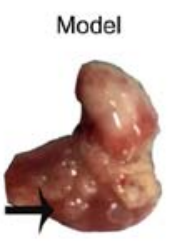

Model

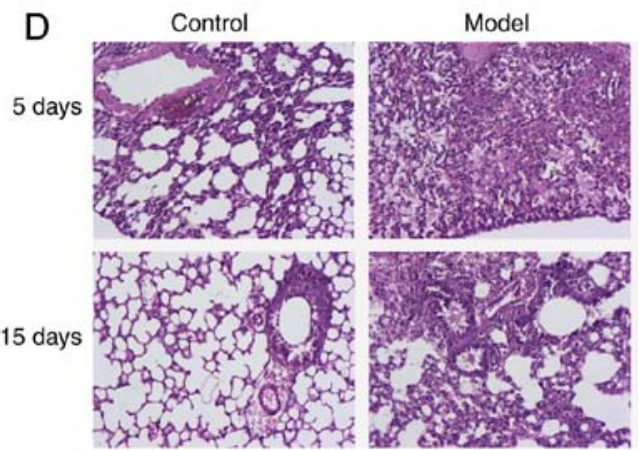

Evo $(5 \mathrm{mg} / \mathrm{kg})$

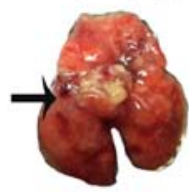

Evo $(5 \mathrm{mg} / \mathrm{kg})$

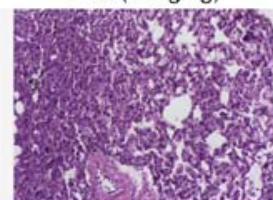

Evo $(10 \mathrm{mg} / \mathrm{kg})$

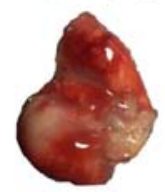

Evo $(10 \mathrm{mg} / \mathrm{kg})$
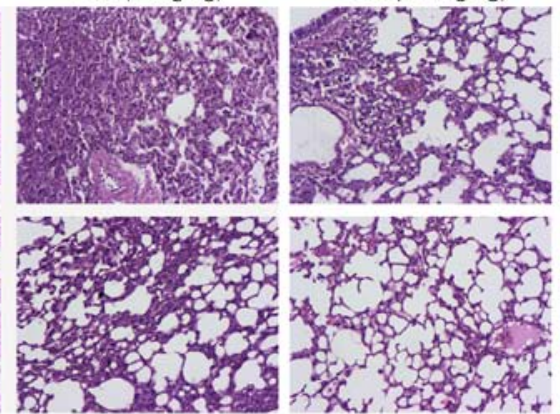

is
Evo $(20 \mathrm{mg} / \mathrm{kg})$

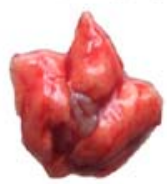

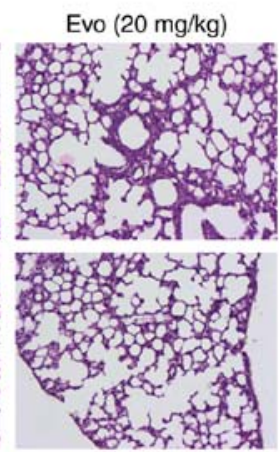

Figure 3. Effects of Evo in mice. Effects of Evo on (A) mortality rate, (B) body weight loss, (C) the morphology (black arrows indicate abscesses) and (D) histological changes of lung tissues (x200) of mice inoculated with MSSA post-cytomegalovirus reactivation. The lungs of mice were collected 5 and 15 days following staphylococcal pneumonia. Data are shown as the mean \pm standard deviation. ${ }^{\# \#} \mathrm{P}<0.01$, vs. control group; ${ }^{*} \mathrm{P}<0.05$ and ${ }^{* * *} \mathrm{P}<0.01$, vs. Model group. Evo, evodiamine; MSSA, methicillin-susceptible Staphylococcus aureus. 

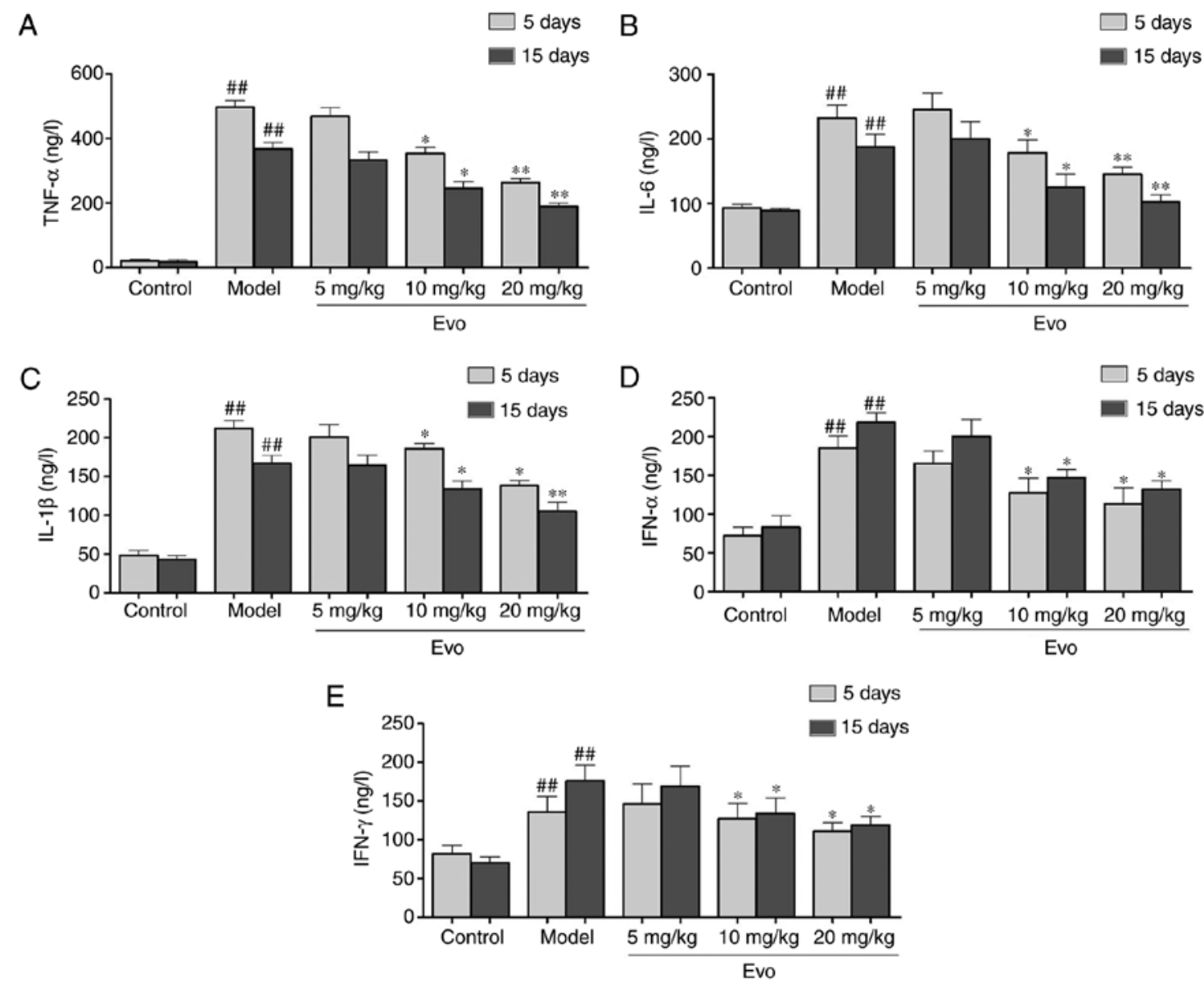

Figure 4. Evo inhibits the secretion of inflammatory cytokines in mice. Evo decreased the secretion of inflammatory cytokines in serum of mice with staphylococcal pneumonia following cytomegalovirus reactivation. The levels of (A) TNF- $\alpha$, (B) IL-1 $\beta$, (C) IL-6, (D) IFN- $\alpha$ and (E) IFN- $\gamma$ were detected by enzyme-linked immunosorbent assay. Data are shown as the mean \pm standard deviation. ${ }^{\#} \mathrm{P}<0.05$ and ${ }^{\# \#} \mathrm{P}<0.01$, vs. control group; ${ }^{*} \mathrm{P}<0.05$ and ${ }^{* *} \mathrm{P}<0.01$, vs. Model group. Evo, evodiamine; MSSA, methicillin-susceptible Staphylococcus aureus; TNF- $\alpha$, tumor necrosis factor- $\alpha$; IL, interleukin; IFN, interferon.
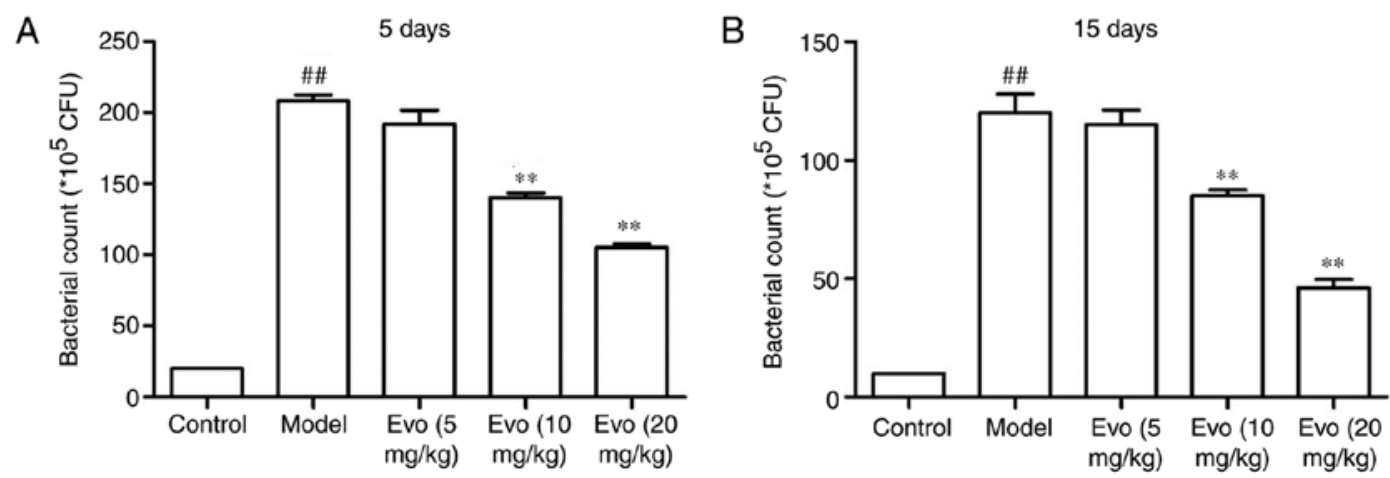

Figure 5. Effects of Evo on lung bacteria count. Evo reduced the lung bacteria count at (A) 5 days and (B) 15 days in mice with staphylococcal pneumonia following cytomegalovirus reactivation. Data are shown as the mean \pm standard deviation. ${ }^{\# \#} \mathrm{P}<0.01$, vs. control group; ${ }^{* *} \mathrm{P}<0.01$, vs. MCMV group. Evo, evodiamine; MSSA, methicillin-susceptible Staphylococcus aureus.

lung abscesses (Fig. 3C). Overall, 30.5\% mice had developed abscessing pneumonia in the MCMV group whereas none was noted in the control group. Following the administration of Evo, with the exception of the Evo $(5 \mathrm{mg} / \mathrm{kg})$ group, the lung abscesses were largely improved.

As shown in Fig. 3D, no evident histological abnormalities were observed in the control group. By contrast, the lung tissues of the MCMV group exhibited severe pathologic changes, including infiltration of inflammatory cells, alveolar wall thickening and alveolar hemorrhage. However, these histopathological changes were significantly reversed following treatment with Evo (10 and $20 \mathrm{mg} / \mathrm{kg}$ ).

Evo inhibits the secretion of inflammatory cytokines. As shown in Fig. 4, the levels of TNF- $\alpha$, IL-1 $\beta$ and IL-6 were significantly increased in the MCMV mice compared with those in the control group. By contrast, with the exception of Evo $(5 \mathrm{mg} / \mathrm{kg})$, pretreatment with Evo (10 and $20 \mathrm{mg} / \mathrm{kg}$ ) efficiently reduced 

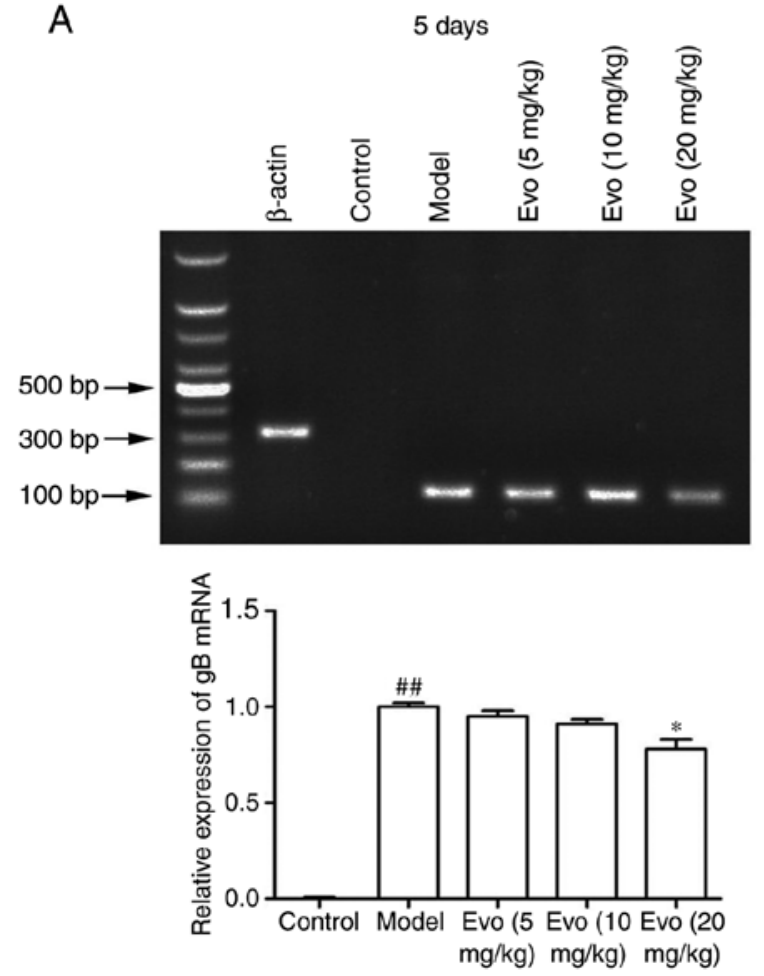

B
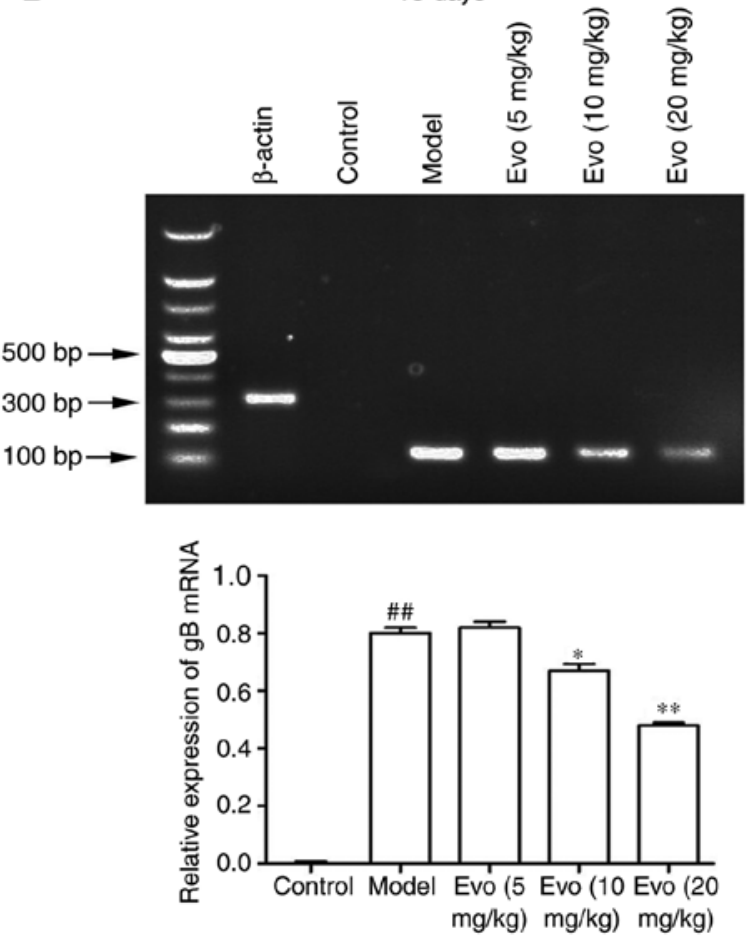

Figure 6. Effect of Evo on mRNA levels of gB. mRNA levels of gB at (A) 5 days and (B) 15 days in mice with staphylococcal pneumonia following cytomegalovirus reactivation were determined using reverse transcription-quantitative polymerase chain reaction analysis. The graph shows the quantification of results normalized to $\beta$-actin levels. Data are shown as the mean \pm standard deviation. ${ }^{\# \#} \mathrm{P}<0.01$, vs. control group; ${ }^{*} \mathrm{P}<0.05$ and ${ }^{* *} \mathrm{P}<0.01$, vs. Model group. Evo, evodiamine; $\mathrm{gB}$, glycoprotein-B.

the production of inflammatory cytokines (Fig. 4A-C). In addition, the levels of IFN- $\alpha$ and IFN- $\gamma$ in the Evo (10 and $20 \mathrm{mg} / \mathrm{kg}$ )-treated mice were reduced in comparison with those in the MCMV group (Fig. 4D and E).

Evo decreases lung bacteria count. As shown in Fig. 5, the lung bacterial count of mice at 5 days post-MSSA pneumonia was higher in the MCMV group. Treatment with Evo (10 and $20 \mathrm{mg} / \mathrm{kg}$ ) facilitated bacterial clearance (Fig. 5A). On day 15, the lung bacterial counts of the Evo groups were also significantly decreased (Fig. 5B).

Evo inhibits the mRNA expression of $g B$. The mRNA levels of $\mathrm{gB}$ in the lung tissues were determined using RT-qPCR analysis to confirm whether Evo inhibited staphylococcal pneumonia following CMV reactivation. As shown in Fig. 6A and B, the mRNA content of the $\mathrm{gB}$ gene in the MCMV group was significantly increased, whereas no virus was detected in the control group. By contrast, Evo (10 and $20 \mathrm{mg} / \mathrm{kg}$ ) at 15 days post-infection had effectively inhibited the amplification of the gB gene.

Evo suppresses the MAPK/NF- $\kappa B$ pathways. MCMV stimulation induced the levels of $\mathrm{p}-\mathrm{I} \kappa \mathrm{B} \alpha$ in the cytoplasm and of p65 in the nucleus. By contrast, Evo (10 and $20 \mathrm{mg} / \mathrm{kg}$ ) markedly inhibited the $\mathrm{p}-\mathrm{I} \kappa \mathrm{B} \alpha$ and the nuclear translocation of p65NF-кB (Fig. 7A). Similarly, with the exception of the $5 \mathrm{mg} / \mathrm{kg}$ concentration of Evo, treatment with Evo (10 and $20 \mathrm{mg} / \mathrm{kg}$ ) efficiently reduced the levels of p-p38, p-JNK and p-ERK in a dose-dependent manner (Fig. 7B).

\section{Discussion}

Evo is a botanical alkaloid component extracted from the traditional Chinese medicinal herb Wu-Zhu-Yu (Evodiae fructus) and has various pharmacological properties. A patent review indicated the anticancer, antidiabetic and anti-inflammatory properties of Evo and also showed that relevant clinical studies of Evo possess important market potential for the development of based therapeutics (18). Evo also effectively suppresses inflammation by repressing inflammatory cytokine expression and ameliorating the abnormal state in the lung by inactivating NF- $\kappa \mathrm{B}$ and $\mathrm{p}-\mathrm{I} \kappa \mathrm{B} \alpha(19)$. IL- $1 \beta$ often acts synergistically with TNF- $\alpha$ and IL-6, producing a variety of chemotactic cytokines which are involved in the inflammatory cytokine cascade (20). The increased levels of IL-1 $\beta$, IL-6 and TNF- $\alpha$ can facilitate immunosuppression, which will promote secondary bacterial infection (21). In addition, IFN- $\alpha$ and IFN- $\gamma$ have also been characterized in the immune response in post-viral immunosuppression and susceptibility to bacteria (22). In the present study, Evo dose-dependently reduced the protein and mRNA expression levels of TNF- $\alpha$, IL-6 IL-1 $\beta$, IFN- $\alpha$ and IFN- $\gamma$ in vitro and in vivo. Lung bacterial count was higher in MCMV mice exposed to $S$. aureus inhalation, which suggested an impairment of lung bacterial clearance following reactivation of CMV, whereas Evo reversed this effect. Therefore the preventive effect of Evo on tissue destruction in the host may minimize disturbance of the host defense system. CMV gB encodes the viral envelope glycoprotein, which is closely associated with virus adsorption and fusion during the viral proliferation cycle. When the 

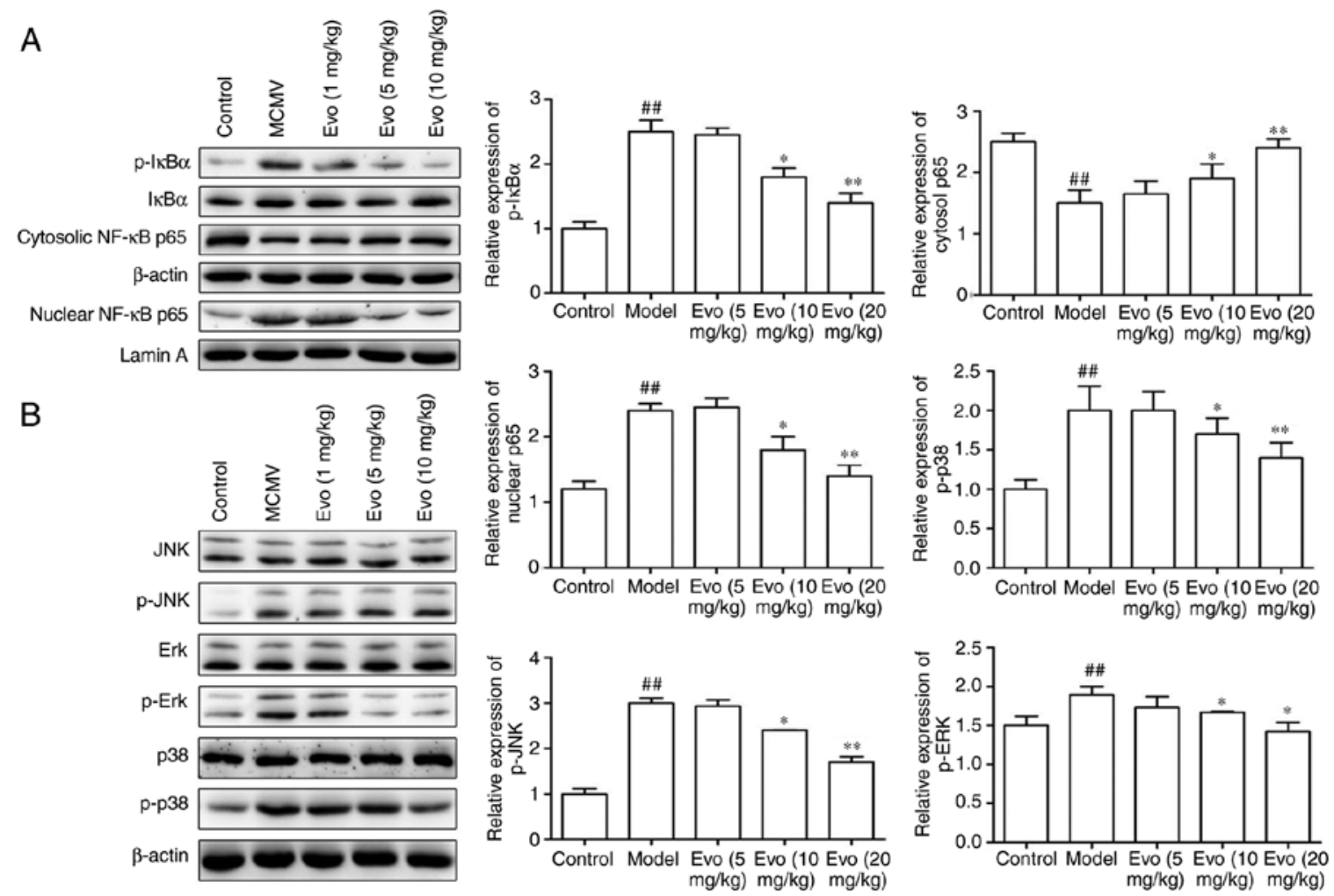

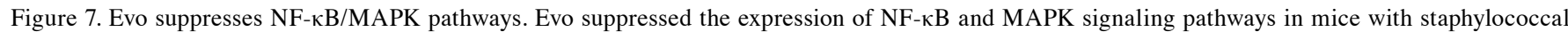

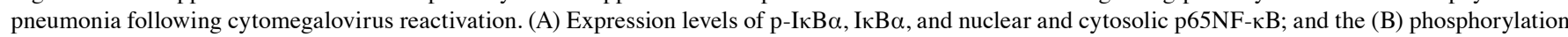
of ERK, JNK and p38 were detected by western blot analysis. The graph shows the quantification of results normalized to $\beta$-actin or Lamin A levels. Data are shown as the mean \pm standard deviation. ${ }^{\# /} \mathrm{P}<0.01$, vs. control group; ${ }^{*} \mathrm{P}<0.05$ and ${ }^{* *} \mathrm{P}<0.01$, vs. MCMV/Model group. Evo, evodiamine; MCMV, mouse cytomegalovirus; MAPK, mitogen-activated protein kinase; NF- $\mathrm{B}$, nuclear factor- $\kappa \mathrm{B}$; I $\mathrm{B}$, inhibitor of NF- $\mathrm{B}$; JNK, c-Jun N-terminal kinase; ERK, extracellular signal-regulated kinase; p-, phosphorylated.

gB gene transcript disappears in the host body, MCMV can no longer proliferate (23). The RT-qPCR analysis showed that Evo alleviated staphylococcal pneumonia by suppressing amplification of the $\mathrm{gB}$ gene. These findings suggested that the protective effects of Evo on staphylococcal pneumonia were partly attributed to the suppressed modification of the host's immunity following MCMV reactivation.

The NF- $\kappa \mathrm{B}$ and MAPK pathways have fundamental roles in controlling the induction and regulation of inflammatory and immune responses. The activation of $\mathrm{NF}-\kappa \mathrm{B}$ can regulate the expression of the specific target gene of pro-inflammatory cytokines, and are also present in several diseases, including asthma, septic shock and lung fibrosis $(24,25)$. MAPKs are closely associated with the expression of inflammatory cytokines and chemokines upon pathogen challenge. The phosphorylation of ERK, JNK and p38 MAPKs can also activate NF-Kb (26). Previous studies have suggested that Evo inhibits the migration and invasiveness of NPC cells accounting for the inactivation of NF- $\kappa$ B and MAPKs (27). In the present study, Evo inhibited p-I $\kappa \mathrm{B} \alpha$, and the nuclear translocation of NF- $\mathrm{B}$ p 65 , p-p38, p-JNK and p-ERK MAPKs, which suggested that the inhibitory effect of Evo on staphylococcal pneumonia may be associated with inactivation of the $\mathrm{NF}-\kappa \mathrm{B}$ and MAPK signaling pathways.

In conclusion, the present study demonstrated that Evo alleviated severe pneumonia inoculated with $S$. aureus following $\mathrm{CMV}$ reactivation by inactivating the $\mathrm{NF}-\kappa \mathrm{B}$ and MAPK pathways, and these results may facilitate further investigation of its potential clinical applications for pneumonia.

\section{Acknowledgements}

Not applicable.

\section{Funding}

No funding was received.

\section{Availability of data and materials}

All data generated or analysed during this study are included in this published article.

\section{Authors' contributions}

HL contributed to the design of the study. XC and SZ contributed to the acquisition, collection and assembly of the data. XC contributed to the statistical analysis. $\mathrm{XC}$ wrote the main manuscript text. All authors read and approved the final manuscript.

\section{Ethics approval and consent to participate}

Animal welfare and experimental procedures were approved by the Animal Experimental Ethical Committee of Soochow University. 


\section{Patient consent for publication}

Not applicable.

\section{Competing interests}

The authors declare that they have no competing interests.

\section{References}

1. Fraser CS, Jha A and Openshaw PJ: Vaccines in the prevention of viral pneumonia. Clin Chest Med 38: 155-169, 2017.

2. Rudan I, O'Brien KL, Nair H, Liu L, Theodoratou E, Qazi S Lukšić I, Fischer Walker CL, Black RE and Campbell H; Child Health Epidemiology Reference Group (CHERG): Epidemiology and etiology of childhood pneumonia in 2010: Estimates of incidence, severe morbidity, mortality, underlying risk factors and causative pathogens for 192 countries. J Glob Health 3: 010401, 2013.

3. Choi J, Kim YS, Kim MS, Callaway Z, Youn UK, Kim HB and $\mathrm{Kim} \mathrm{CK}$ : Acute respiratory distress syndrome by cytomegalovirus infection in an immunocompetent infant. Pediatr Pulmonol 43: 824-827, 2008.

4. Hanley PJ and Bollard CM. Controlling cytomegalovirus: Helping the immune system take the lead. Viruses 6: 2242-2258, 2014.

5. Liu L, Oza S, Hogan D, Perin J, Rudan I, Lawn JE, Cousens S, Mathers C and Black RE: Global, regional, and national causes of child mortality in 2000-13, with projections to inform post-2015 priorities: An updated systematic analysis. Lancet 385: 430-440, 2015.

6. Casiraghi C, Shanina I, Cho S, Freeman ML, Blackman MA and Horwitz MS: Gammaherpesvirus latency accentuates EAE pathogenesis: Relevance to Epstein-Barr virus and multiple sclerosis. PLoS Pathog 8: e1002715, 2012.

7. Sinclair J: Human cytomegalovirus: Latency and reactivation in the myeloid lineage. J Clin Virol 41: 180-185, 2008.

8. Hsiao NY, Zampoli M, Morrow B, Zar HJ and Hardie D: Cytomegalovirus viraemia in HIV exposed and infected infants: Prevalence and clinical utility for diagnosing CMV pneumonia. J Clin Virol 58: 74-78, 2013.

9. Ascherio A and Munger KL: Environmental risk factors for multiple sclerosis. Part I: The role of infection. Ann Neurol 61: 288-299, 2007.

10. Lv Q, Xue Y, Li G, Zou L, Zhang X, Ying M, Wang S, Guo L, Gao Y, Li G, et al: Beneficial effects of evodiamine on P2X(4)-mediated inflammatory injury of human umbilical vein endothelial cells due to high glucose. Int Immunopharmacol 28: 1044-1049, 2015.

11. Ying Z, Xia F, Xue Y, Huaping L and Yan L: Evodiamine protects septic mice against acute lung injury. $J$ Third Military Med Univ 21: 2309-2314, 2016.

12. Zhang C,Fan X, Xu X, Yang X, Wang X and Liang HP: Evodiamine induces caspase-dependent apoptosis and $S$ phase arrest in human colon lovo cells. Anticancer Drugs 21: 766-776, 2010.

13. Wang C, Li S and Wang MW: Evodiamine-induced human melanoma A375-S2 cell death was mediated by PI3K/Akt/caspase and Fas-L/NF-kappa B signaling pathways and augmented by ubiquitin-proteasome inhibition. Toxicol In Vitro 24: 898-904, 2010 .

14. Yang J, Cai X, Lu W, Hu C, Xu X, Yu Q and Cao P: Evodiamine inhibits STAT3 signaling by inducing phosphatase shatterproof 1 in hepatocellular carcinoma cells. Cancer Lett 328: 243-251, 2013 .
15. Zhao T: Neuroprotection of eodiamine in the cerebral ischemia: Up-regulated pAkt, p GSK, claudin-5 and down-regulated NF- $\kappa \mathrm{B}$ expression. Hebei Medical University, CLC: R96, 2013. https://www.dissertationtopic.net/doc/1843193.

16. Hraiech S, Bordes J, Mège JL, de Lamballerie X, Charrel R, Bechah Y, Pastorino B, Guervilly C and Forel JM: Cytomegalovirus reactivation enhances the virulence of Staphylococcus aureus pneumonia in a mouse model. Clin Microbiol Infect 23: 38-45, 2017.

17. Livak KJ and Schmittgen TD: Analysis of relative gene expression data using real-time quantitative PCR and the $2^{-\Delta \Delta C_{\mathrm{T}}}$ method. Methods 25: 402-408, 2001.

18. Gavaraskar K, Dhulap S and Hirwani RR: Therapeutic and cosmetic applications of Evodiamine and its derivatives-A patent review. Fitoterapia 106: 22-35, 2015.

19. Fan X, Zhu JY, Sun Y, Luo L, Yan J, Yang X, Yu J, Tang WQ, Ma W and Liang HP: Evodiamine inhibits Zymosan-induced inflammation in vitro and in vivo: Inactivation of $\mathrm{NF}-\kappa \mathrm{B}$ by inhibiting I $\mathrm{B} \alpha$ phosphorylation. Inflammation 40: 1012-1027, 2017.

20. Chi G, Wei M, Xie X, Soromou LW,Liu F and Zhao S: Suppression of MAPK and NF- $\kappa$ B pathways by limonene contributes to attenuation of lipopolysaccharide-induced inflammatory responses in acute lung injury. Inflammation 36: 501-511, 2013.

21. Hraiech S, Papazian L, Rolain JM and Bregeon F: Animal models of polymicrobial pneumonia. Drug Des Devel Ther 9: 3279-3292, 2015

22. Shahangian A, Chow EK, Tian X, Kang JR, Ghaffari A, Liu SY, Belperio JA, Cheng G and Deng JC: Type I IFNs mediate development of postinfluenza bacterial pneumonia in mice. $\mathrm{J}$ Clin Invest 119: 1910-20, 2009.

23. Zavala-Vega S, Castro-Escarpulli G, Hernández-Santos $H$, Salinas-Lara C, Palma I, Mejía-Aranguré JM, Gelista-Herrera N, Rembao-Bojorquez D, Ochoa SA, Cruz-Córdova A, et al: An overview of the infection of CMV, HSV 1/2 and EBV in Mexican patients with glioblastoma multiforme. Pathol Res Pract 213: 271-276, 2017.

24. Kim J, Woo J, Lyu JH, Song HH, Jeong HS, Ha KT, Choi JY, Han CW, Ahn KS, Oh SR, et al: Carthami Flos suppresses neutrophilic lung inflammation in mice, for which nuclear factor-erythroid 2-related factor-1 is required. Phytomedicine 21: 470-478, 2014.

25. DiDonato JA, Mercurio F and Karin $M: N F-\kappa B$ as a critical link between inflammation and cancer. Immunol Rev 246: 379-400, 2012.

26. Kim HI, Hong SH, Ku JM, Kang S, Kim TY, Shin YC and Ko SG: Tonggyu-tang, a traditional Korean medicine, suppresses pro-inflammatory cytokine production through inhibition of MAPK and NF- $\kappa$ B activation in human mast cells and keratinocytes. BMC Complement Altern Med 17: 186, 2017.

27. Takada Y, Kobayashi Y and Aggarwal BB: Evodiamine abolishes constitutive and inducible NF-kappaB activation by inhibiting IkappaBalpha kinase activation, thereby suppressing NF-kappaB-regulated antiapoptotic and metastatic gene expression, up-regulating apoptosis, and inhibiting invasion. J Biol Chem 280: 17203-17212, 2005.

This work is licensed under a Creative Commons Attribution-NonCommercial-NoDerivatives 4.0 International (CC BY-NC-ND 4.0) License. 